\title{
Transcriptomic Analysis of Pseudomonas aeruginosa Response to Pine Honey via RNA Sequencing Indicates Multiple Mechanisms of Antibacterial Activity
}

\author{
Ioannis Kafantaris ${ }^{1,+}$, Christina Tsadila ${ }^{1,+}{ }^{\mathbb{D}}$, Marios Nikolaidis ${ }^{2}$, Eleni Tsavea ${ }^{1}$, Tilemachos G. Dimitriou ${ }^{1} \mathbb{D}$, \\ Ioannis Iliopoulos ${ }^{3}$, Grigoris D. Amoutzias ${ }^{2}$ (D) and Dimitris Mossialos $1, *$ D
}

1 Microbial Biotechnology-Molecular Bacteriology-Virology Laboratory, Department of Biochemistry \& Biotechnology, University of Thessaly, Biopolis, 41500 Larissa, Greece; kafantarisioannis@gmail.com (I.K.); tsadila@uth.gr (C.T.); elenats89@hotmail.com (E.T.); tidimitr@bio.uth.gr (T.G.D.)

2 Bioinformatics Laboratory, Department of Biochemistry \& Biotechnology, University of Thessaly, Biopolis, 41500 Larissa, Greece; marionik23@gmail.com (M.N.); amoutzias@bio.uth.gr (G.D.A.)

3 Department of Basic Sciences, School of Medicine, University of Crete, 71003 Heraklion, Greece; iliopj@med.uoc.gr

* Correspondence: mosial@bio.uth.gr; Tel.: +30-2410-565270

+ These authors contributed equally.

check for updates

Citation: Kafantaris, I.; Tsadila, C.; Nikolaidis, M.; Tsavea, E.; Dimitriou, T.G.; Iliopoulos, I.; Amoutzias, G.D.; Mossialos, D. Transcriptomic Analysis of Pseudomonas aeruginosa Response to Pine Honey via RNA Sequencing Indicates Multiple Mechanisms of Antibacterial Activity. Foods 2021, 10, 936. https://doi.org/ $10.3390 /$ foods 10050936

Academic Editors: Yelko Rodríguez-Carrasco and Bojan Šarkanj

Received: 5 April 2021

Accepted: 22 April 2021

Published: 24 April 2021

Publisher's Note: MDPI stays neutral with regard to jurisdictional claims in published maps and institutional affiliations.

Copyright: (c) 2021 by the authors. Licensee MDPI, Basel, Switzerland. This article is an open access article distributed under the terms and conditions of the Creative Commons Attribution (CC BY) license (https:// creativecommons.org/licenses/by/ $4.0 /)$

\begin{abstract}
Pine honey is a unique type of honeydew honey produced exclusively in Eastern Mediterranean countries like Greece and Turkey. Although the antioxidant and anti-inflammatory properties of pine honey are well documented, few studies have investigated so far its antibacterial activity. This study investigates the antibacterial effects of pine honey against $P$. aeruginosa PA14 at the molecular level using a global transcriptome approach via RNA-sequencing. Pine honey treatment was applied at sub-inhibitory concentration and short exposure time $(0.5 \times$ of minimum inhibitory concentration -MIC- for $45 \mathrm{~min}$ ). Pine honey induced the differential expression (>two-fold change and $p \leq 0.05$ ) of 463 genes, with 274 of them being down-regulated and 189 being up-regulated. Gene ontology (GO) analysis revealed that pine honey affected a wide range of biological processes (BP). The most affected down-regulated BP GO terms were oxidation-reduction process, transmembrane transport, proteolysis, signal transduction, biosynthetic process, phenazine biosynthetic process, bacterial chemotaxis, and antibiotic biosynthetic process. The up-regulated BP terms, affected by pine honey treatment, were those related to the regulation of DNA-templated transcription, siderophore transport, and phosphorylation. Pathway analysis revealed that pine honey treatment significantly affected two-component regulatory systems, ABC transporter systems, quorum sensing, bacterial chemotaxis, biofilm formation and SOS response. These data collectively indicate that multiple mechanisms of action are implicated in antibacterial activity exerted by pine honey against $P$. aeruginosa.
\end{abstract}

Keywords: Pseudomonas aeruginosa; pine honey; RNA-sequencing; antimicrobial activity; transcriptomics; biological process

\section{Introduction}

Pseudomonas aeruginosa is a ubiquitous, Gram-negative opportunistic human pathogen that can cause acute and chronic human infections in hospitalized or immune-compromised patients [1,2]. Typically, it infects the airway, urinary tract, burns, wounds, surgical site infections and also causes systemic blood infections that can lead to death [3]. The pathogenesis of $P$. aeruginosa is attributed to a variety of virulence factors, such as the cytotoxic pigment pyocyanin, the major siderophore pyoverdine, alkaline protease, elastase, exotoxins, flagella, and biofilm formation [4]. In addition, core genome analyses have revealed a distinct set of $P$. aeruginosa specific genes, related to its pathogenicity and lifestyle [5]. $P$. aeruginosa can adapt to a wide variety of environmental conditions and exhibits a remarkable high multidrug resistance by the formation of biofilms [6-8]. Considering its high 
prevalence associated with high mortality rates and lack of treatment options, this pathogen has been identified by the World Health Organization as a critical research priority for the development of alternative drugs and novel therapeutic strategies [9].

Recently, diverse natural products exerting antimicrobial activity have been widely investigated as alternative therapeutic agents to combat multidrug resistant pathogens. Honey, a natural product of honey bees, has been traditionally used in treating wounds and infectious diseases [10-12]. Many studies have proved the antimicrobial activity of different honey types against a plethora of pathogenic bacteria [13-17]. Previous studies conducted by our research group have also demonstrated that Greek and Cypriot honeys of diverse botanical origin exhibited potent antibacterial activity [18-20]. The antibacterial activity of honey to a wide range of pathogens is due to multiple factors including hydrogen peroxide $\left(\mathrm{H}_{2} \mathrm{O}_{2}\right)$, low $\mathrm{pH}$, methylglyoxal (MGO), antimicrobial peptides, and osmotic stress $[16,21,22]$. Several studies have shown numerous biological processes in bacteria that may be affected by honey such as protein synthesis, quorum sensing (QS), motility, biofilm formation, as well as response to oxidative stress [23-26].

Pine honey, is a unique type of honeydew honey produced in Eastern Mediterranean Pinus brutia and Pinus halepensis Miller forests, located in Greece and Turkey [27]. It is produced by bees which collect honeydew (sugary secretions) eliminated by the insect Marchalina hellenica (Gennadius), when feeding on certain pine trees [28]. Pine honey has an impressive pearl-amber color with characteristic metallic highlights, a spicy taste, as well as a thick texture. All the above characteristics combined with its natural property not to crystallize and its high content of minerals (potassium, calcium, iron, phosphorus, magnesium, sodium, and zinc), make pine honey a natural product of significant economic value [29]. It is estimated that in Greece and Turkey pine honey represents, $65 \%$ and 50\% of the total annual honey production, respectively $[30,31]$. Although the antioxidant and anti-inflammatory properties of pine honey are well documented [32-35], few studies have investigated its antibacterial activity $[18,36,37]$.

RNA sequencing (RNA-seq) is a cutting-edge technology for transcriptome profiling that can provide measurements of genome-wide quantitative analysis of all transcripts with high accuracy and sensitivity [38,39]. In addition, RNA-seq can reveal specific biological processes, affected in the presence of natural products or drugs [40,41]. To our knowledge, this is the first study that employs a global transcriptome approach via RNA-seq analysis to investigate the antibacterial effects of pine honey at the molecular level using as a model microorganism the P. aeruginosa PA14 strain.

\section{Materials and Methods}

\subsection{Honey Samples}

Pine honey was harvested in August 2019 from an apiary located in Chalkidiki area (Greece). After the collection, the sample was stored in glass container at room temperature in the dark. Manuka honey UMF 24+ (MGO 1122), Steens ${ }^{\mathrm{TM}}$, New Zealand (Batch No B084E3) was also used in this study.

\subsection{Bacterial Strain, Growth Media, and Culture Conditions}

The antibacterial activities of the pine and manuka honeys were tested upon Pseudomonas aeruginosa PA14 strain. The bacterial strain was routinely grown in Mueller-Hinton (MH) broth or MH agar (Lab M, Bury, UK) at $37^{\circ} \mathrm{C}$.

\subsection{Assessment of the Minimum Inhibitory Concentration (MIC) and Minimum Bactericidal Concentration $(M B C)$}

The minimum inhibitory concentration (MIC) of the tested honey sample was assessed in sterile 96-well polystyrene microtiter plate (Kisker Biotech GmbH \& Co. KG, Steinfurt, Germany) using a spectrophotometric bioassay, as previously described [19]. Briefly, overnight bacterial culture grown in $\mathrm{MH}$ broth was adjusted to a $0.5 \mathrm{McF}$ arland turbidity standard $\left(\sim 1.5 \times 10^{8} \mathrm{cfu} / \mathrm{mL}\right)$. Approximately $5 \times 10^{4} \mathrm{cfu}$ in $10 \mu \mathrm{L}$ MH broth was added 
to $190 \mu \mathrm{L}$ of diluted test honey in MH broth. The control wells contained only MH broth, inoculated with bacteria. The optical density (OD) was determined at $630 \mathrm{~nm}$ using an EL x808 Absorbance microplate reader (BioTek Instruments, Inc., Winooski, VT, USA) before $(t=0)$ and after $24 \mathrm{~h}$ of incubation $(t=24)$ at $37^{\circ} \mathrm{C}$. The OD for each replicate well at $\mathrm{t}=0$ was subtracted from the OD of the same replicate well at $t=24$. The growth inhibition at each honey dilution was measured using the formula: \% inhibition $=1-$ (OD test well $/ O D$ of corresponding control well) $\times 100$. MIC was defined as the lowest honey concentration which results in $100 \%$ growth inhibition.

The MBC is the lowest concentration of any antibacterial agent that could kill tested bacteria. The MBC was determined by transferring a small quantity of sample contained in each replicate well of the microtiter plates to $\mathrm{MH}$ agar plates by using a microplate replicator (Boekel Scientific, Waltham, PA, USA). The plate was incubated at $37^{\circ} \mathrm{C}$ for $24 \mathrm{~h}$. The MBC was determined as the lowest honey concentration at which no grown colonies were observed [42].

\subsection{Assessment of the Antibacterial Activity Attributed to Hydrogen Peroxide and Proteinaceous Compounds}

The MIC of honey treated with bovine catalase or proteinase $\mathrm{K}$ was assessed in comparison to the untreated honey as previously described [18,43]. Briefly, $50 \%(v / v)$ honey in $\mathrm{MH}$ broth containing $100 \mathrm{mg} / \mathrm{mL}$ proteinase K (Blirt, Gdansk, Poland) or $600 \mathrm{U} / \mathrm{mL}$ bovine catalase (Serva, Heidelberg, Germany) was incubated for $16 \mathrm{~h}$ at $37^{\circ} \mathrm{C}$, then diluted and tested as described above. An increased MIC of treated honey compared to the untreated honey has shown that the antibacterial activity of tested honey was attributable to hydrogen peroxide and/or proteinaceous compounds, respectively.

\subsection{Total RNA Isolation and RNA Sequencing}

Pseudomonas aeruginosa PA14 culture was prepared in $\mathrm{MH}$ broth to an initial optical density at $600 \mathrm{~nm}\left(\mathrm{OD}_{600}\right)$ of 0.05 and then incubated in a $250-\mathrm{mL}$ cell culture conical flask (Erlenmeyer, Duran) at $37^{\circ} \mathrm{C}$ with shaking at $200 \mathrm{rpm}$ until reaching mid-exponential phase $\left(\mathrm{OD}_{600}\right.$ of 0.4$)$. Cultures were then split into two conical sterile falcons (Falcon, Corning): one falcon contained $30 \mathrm{~mL}$ of untreated culture (control) and the second falcon $(30 \mathrm{~mL})$ contained the culture and the treatment at a final concentration of roughly $0.5 \times \mathrm{MIC}$ of pine honey $(4.5 \% v / v)$. Each culture was grown for an additional $45 \mathrm{~min}$ before total RNA isolation. The control and the treated culture were then split into three technical replicates (10 $\mathrm{mL}$ each). Total RNA from each replicate was isolated using a NucleoSpin RNA isolation kit (Macherey-Nagel) and DNA removed with DNase I, according to the manufacturer's protocol. Samples were analyzed spectrophotometrically using a microvolume UV-Vis instrument (Quawell, San Jose, CA, USA) for quantification and purity assessment. All RNA samples had an $\mathrm{A}_{260}: \mathrm{A}_{280}$ ratio between 1.8 and 2.0. RNA integrity was initially verified by $1 \%$ agarose gel electrophoresis. The six samples ( 3 controls and 3 treated) were shipped to Macrogen (Seoul, South Korea) for rRNA depletion using a NEBNext Bacterial rRNA removal kit (Illumina, San Diego, CA, USA), library preparation using the TruSeq stranded total RNA kit (Illumina, San Diego, CA, USA), and subsequent 150-bp paired-end RNA sequencing on a NovaSeq6000 platform (Illumina, San Diego, CA, USA). RNA integrity was further evaluated using the RNA Nano 6000 Assay Kit of the Agilent Bioanalyzer 2100 system (Agilent Technologies, Santa Clara, CA, USA); all samples demonstrated RNA integrity number $(\mathrm{RIN})>$ 8.0.

\subsection{Bioinformatics Analysis of the Differentially Expressed Genes (DEGs)}

The fastq files were downloaded from Macrogen, with adapter trimming applied (TruSeq3 paired-ended) and their read quality was initially assessed using FASTQC (version 0.11.5) (http:/ / www.bioinformatics.babraham.ac.uk/projects/fastqc, accessed on 20 December 2020). Subsequently, the reads were trimmed with Trimmomatic (version 0.38default parameters) [44] and their quality was again assessed. Reads were aligned to the $P$. aeruginosa PA14 genome (NCBI reference sequence, NC_008463.1; GenBank ac- 
cession number CP000438.1; assembly GCA_000014625.1) using the alignment program HISAT2 [45] and subsequently the number of reads that mapped to each gene was counted using the feature counts tool (version 1.6.4) with default parameters [46]. After mapping and counting, differential expression analysis, between control and treated samples, was carried out using the DESeq2 package (version 2.11.39) [47]. Gene annotation was carried out using the tool of DESeq2 package and the appropriate file (gtf) from the assembly (GCA_000014625.1). Genes whose expression displayed an average fold change $>2$ and was statistically significant (adjusted $p$ value $\leq 0.05$ ) were considered differentially expressed (DEGs). In order to understand more profoundly the biological functions and the metabolic pathways of the identified genes, the DEGs were functionally classified due to Gene Ontology (GO), using the Goseq tool (version 3.12) [48] and Kyoto Encyclopedia of Genes and Genomes (KEGG) database (http:/ / www.genome.jp/kegg/, accessed on 27 December 2020) [49]. Go annotation and KEGG classifications were downloaded from the Pseudomonas Community Annotation Project (PseudoCAP) [50].

A second RNA sequencing analysis using a different pipeline was also conducted for assessing the robustness of the RNA-seq analysis conclusions. Briefly, the fastq files were trimmed with minimum contig length parameters and the quality of the final reads was inspected with FastQC. The trimmed fastq files were used for the de novo assembly of the P. aeruginosa PA14 transcriptome with the Trinity software (default parameters) [51], using all samples together. The resulting 5674 Trinity contigs were filtered to keep the longest isoform of each trinity gene, thus retaining 4903 contigs. The 4903 contigs were fed to TransDecoder software (https:/ / github.com/TransDecoder/TransDecoder, accessed on 15 January 2021) with default parameters to identify the putative ORFs. Next the resulting 15,549 TransDecoder CDS were used as database for BLASTn search while the P. aeruginosa PA14 (GCA_000014625.1) CDS were used as a query with e-value cut-off $1 \times 10^{-5}$. The best BLAST hit was kept for each P. aeruginosa PA14 gene, resulting in 4614 TransDecoder CDS. Next, Bowtie2 [52] within Trinity was used to align the reads back to the 4,614 TransDecoder CDS. In addition to the Trinity de novo assembly, a reference guided analysis was also performed by aligning the trimmed reads to the P. aeruginosa PA14 CDS with Bowtie2. Identification of DEGs in both analyses was conducted with the edgeR package [53] within Trinity, using default parameters.

\section{Results and Discussion}

\subsection{Antibacterial Activity of Pine Honey against P. aeruginosa PA14}

In order to investigate the activity of pine honey against $P$. aeruginosa, MIC and MBC values were determined. Data are presented in Table 1.

Table 1. Antibacterial activity of pine honey and manuka against $P$. aeruginosa.

\begin{tabular}{ccccc}
\hline Honey & MIC $\%(v / v)^{\mathbf{1}}$ & MBC $\%(v / v)^{\mathbf{2}}$ & MICp $\%(v / v)^{3}$ & MICc $\%(v / v)^{4}$ \\
\hline pine honey & 9 & 9 & 9 & 20 \\
manuka & 9 & 11 & ND $^{5}$ & ND \\
\hline
\end{tabular}

${ }^{1} \mathrm{MIC}$, minimum inhibitory concentration. ${ }^{2} \mathrm{MBC}$, minimum bactericidal concentration. ${ }^{3} \mathrm{MICp}$, MIC values of proteinase $\mathrm{K}$ treated honey. ${ }^{4} \mathrm{MICc}$, MIC values of catalase treated honey. ${ }^{5} \mathrm{ND}$, not determined.

The results clearly demonstrate that pine honey and manuka exert high anti-bacterial activity since both inhibited P. aeruginosa at $9 \%(v / v)$. Furthermore, pine honey was bactericidal at $9 \%(v / v)$, while manuka was bactericidal at $11 \%(v / v)$. In order to investigate the mechanisms which may contribute to the anti-bacterial activity, pine honey was treated with catalase and proteinase $\mathrm{K}$. The proteinase $\mathrm{K}$ treated pine honey exhibited MIC value $9 \%(v / v)$ against $P$. aeruginosa, which is the same as the untreated honey, while the catalase treated honey exhibited higher MIC value $20 \%(v / v)$ indicating that the anti-bacterial activity of the pine honey was mainly attributable to hydrogen peroxide and not to proteinaceous compounds (Table 1). On the other hand, it is known that MGO is the main antimicrobial compound in manuka honey [22]. 


\subsection{Effects of Pine Honey on the Transcriptomic Profile of P. aeruginosa PA14}

3.2.1. Global Response of P. aeruginosa to Pine Honey Treatment

The molecular response of $P$. aeruginosa to pine honey was investigated using RNASeq. Pine honey treatment was applied at sub-inhibitory concentration and short exposure time (0.5 $\times$ MIC for $45 \mathrm{~min})$, since this approach induces more specific response and reduces indirect effects [54]. A sub-inhibitory concentration may act as stress inducer or cues/coercion on receiver bacteria [55].

Data analysis of DEGs was conducted using three different pipelines, leading to very similar results and conclusions. RNA-seq analysis, using the pipeline (HISAT2featurecounts-DESeq2), revealed that pine honey significantly affects the transcriptomic profile of $P$. aeruginosa PA14 compared to the control, with changes to the expression of 2543 out of 5964 coding sequences $(42.6 \% ; p \leq 0.05)$. Of those 2543 genes, 1257 were up-regulated ( $21 \%$ of all coding genes) and 1286 were down-regulated $(21.6 \%)$. The second pipeline (de novo Trinity-edgeR) revealed that pine honey induced the differential expression of 2115 out of 4673 genes $(45.2 \% ; p \leq 0.05)$, where 1112 were up-regulated (23.8\% of all coding genes) and 1103 were down-regulated (23.6\%). In addition, the third pipeline (reference genome guided analysis-Bowtie2-edgeR) showed that pine honey induced the differential expression of 2451 out of 5964 coding sequences $(41.1 \% ; p \leq 0.05)$ where 1195 were up-regulated ( $20 \%$ of all coding genes) and 1256 were down-regulated (21.1\%). In a similar study, treatment of $P$. aeruginosa PA14 with manuka honey induced the differential expression of 3177 genes $(54 \% ; p \leq 0.05)$ with 1646 of them being up-regulated (representing $28 \%$ of all coding genes) and 1531 being down-regulated (26\% of all coding genes) [56]. Genome-wide expression changes were visualized as heatmap and volcano plot to identify specific genes with high fold changes and statistical significance. Results of hierarchical clustering and volcano plot are shown in Figures 1A and 2.

The results using the first pipeline (HISAT2-featurecounts-DESeq2) showed that pine honey treatment strongly induced the differential expression $\left(\log _{2} \mathrm{FC}>1\right.$, meaning $>$ twofold change and $p \leq 0.05$ ) of 463 genes ( $7.8 \%$ of all coding sequences) including 274 downregulated and 189 up-regulated genes (Table S1). The results of the second pipeline (de novo Trinity-edgeR), revealed that pine honey treatment induced the differential expression $\left(\log _{2} \mathrm{FC}>1\right.$ and $\left.p \leq 0.05\right)$ of 440 genes $(9.4 \%$ of all coding sequences) including 265 down-regulated and 175 up-regulated genes (Table S2). In addition, the last pipeline (reference guided analysis-Bowtie2-edgeR) showed that pine honey induced the differential expression ( $\log _{2} \mathrm{FC}>1$ and $\left.p \leq 0.05\right)$ of 482 genes ( $8.1 \%$ of all coding sequences) including 192 up-regulated and 290 down-regulated genes (Table S3). Further data analysis regarding DEGs was conducted using the pipeline (HISAT2-featurecounts-DESeq2). Compared to the study conducted by Bouzo et al. [56], treatment of P. aeruginosa PA14 with manuka honey highly induced the differential expression of 235 genes $\left(\log _{2} \mathrm{FC}>2\right.$ meaning $>$ four-fold change and $p \leq 0.05$ ) including more up-regulated than down-regulated genes. In Figure 2, genes that were significantly differentially expressed are presented in red (up-regulated) and blue color (down-regulated). The most up- and down-regulated genes are labeled in each plot. In addition, Figure 1B shows the bi-plot of the principal-component analysis of DESeq2 normalized read counts (all coding genes) for pine honey treatment (green) and the control (red), split into technical replicates. Principal component analysis (PCA) confirmed that the effect of pine honey on P. aeruginosa differed significantly relative to the control (Figure 1B). 

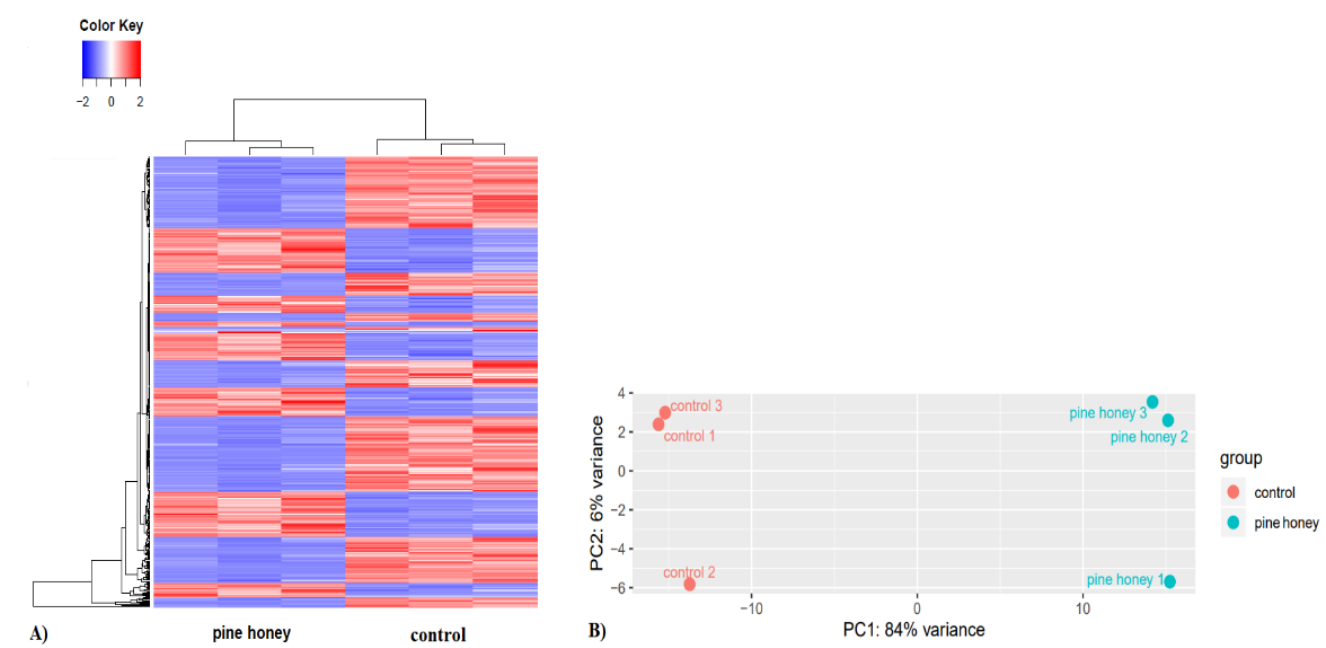

Figure 1. Transcriptional response of $P$. aeruginosa PA14 treated at mid-exponential phase with pine honey for $45 \mathrm{~min}$ at $0.5 \times$ MIC. (A) Clustered heatmap (based on Euclidean measures and complete agglomeration) of all DEGs (>two fold changes and $p$ value $\leq 0.05$ ) in $P$. aeruginosa across pine honey treatment and control. Each column represents one sample, and each row represents one gene. The red and blue gradients indicate up- and down-regulated gene expression, respectively. (B) Bi-plot of the principal-component analysis of DESeq2 normalized read counts (all coding genes) for pine honey treatment (green) and the control (red), split into technical replicates.

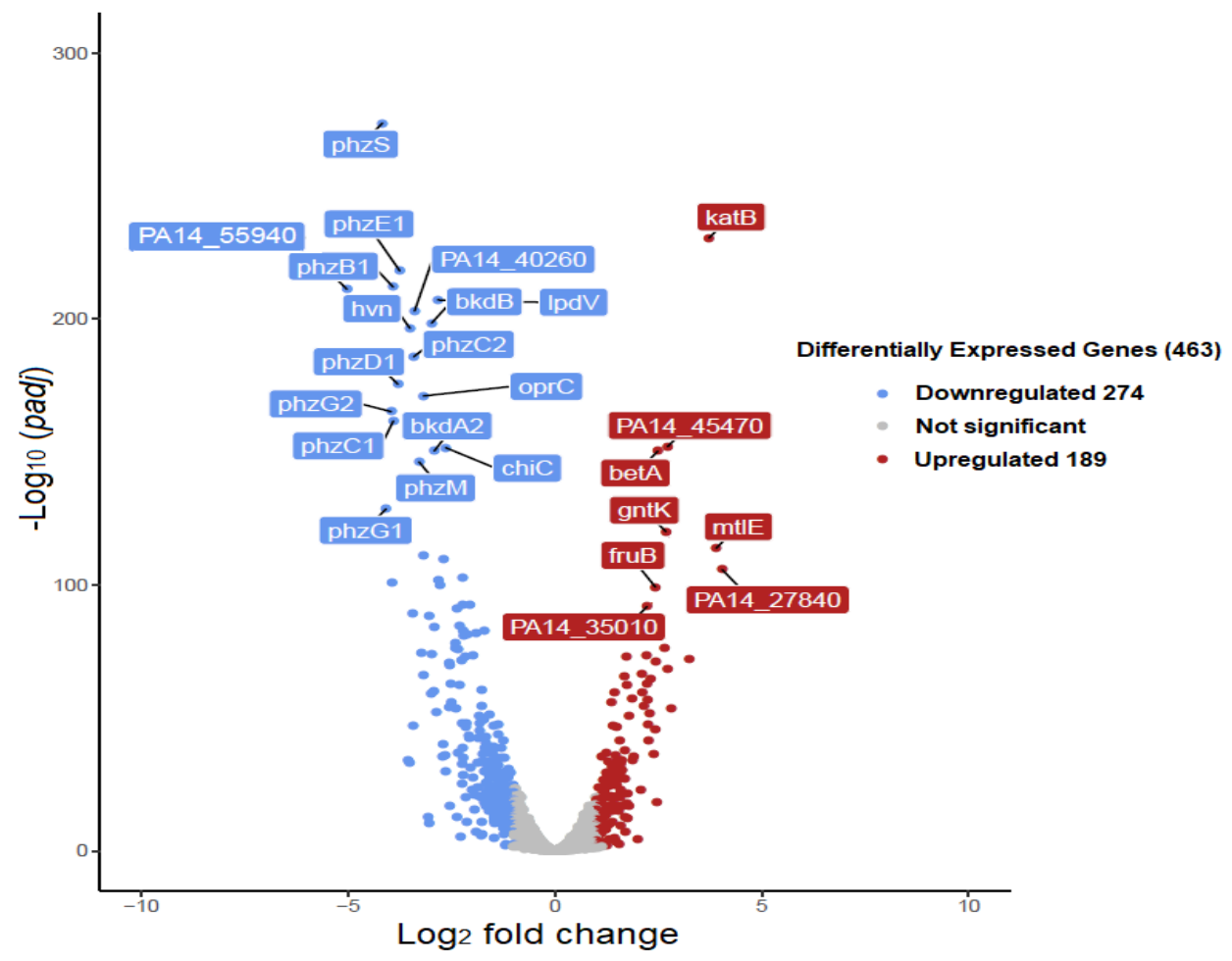

Figure 2. Volcano plot of differentially expressed genes (DEGs) based on RNA-seq analysis of untreated and pine honey-treated Pseudomonas aeruginosa PA14. Each gene is represented by a dot in the graph and the most differentially expressed up-and down-regulated genes are labeled in each plot. The $x$-axis and $y$-axis represent the $\log _{2}$ value of the fold change and the t-statistic as $-\log _{10}$ of the $p$-value, respectively. The genes represented in red (up-regulated) and blue (down-regulated) are differentially expressed genes with $>$ two fold changes and a $p$ value $\leq 0.05$, while gray dots show genes with no significant difference compared to the control. 


\subsubsection{Top Up- and Down-Regulated DEGs}

In the pine honey-treated samples, the genes $k a t B, P A 14 \_45470$, bet $A$, gntK, $m t l E$, fruB, PA14_27840, and PA14_35010 were among the top up-regulated. These genes encode the catalase enzyme $k a t B\left(\log _{2} \mathrm{FC} 3.72\right)$, a putative glutathione S-transferase, the choline dehydrogenase bet $A$, a gluconokinase, a putative binding protein component of $\mathrm{ABC}$ maltose/mannitol transporter $\left(\log _{2} \mathrm{FC} 3.89\right)$, a putative phosphotransferase system fructose-specific component, a putative copper-binding protein $\left(\log _{2} \mathrm{FC} 4.01\right)$ and a hypothetical protein respectively (Figure 2). It is documented that the catalase enzyme katB and glutathione S-transferases are induced in the presence of hydrogen peroxide. Moreover, these enzymes play multiple crucial roles in oxidative stress protection and bacterial virulence in $P$. aeruginosa [57-59]. Another enzyme, the choline dehydrogenase $b e t A$ contributes toward the hyperosmotic stress resistance in Pseudomonas protegens [60]. Therefore the observed transcriptional response clearly shows that $P$. aeruginosa cells attempt to adapt to the hostile environment of pine honey, which is characterized by the presence of hydrogen peroxide and high osmolarity.

Among the genes that were strongly down-regulated were those encoding proteins involved in phenazine biosynthesis phzB1, C1, C2, D1, E1 ( $\log _{2} \mathrm{FC}$ ranged from -3.40 to -3.90), PA14_55940 $\left(\log _{2} \mathrm{FC}-5.20\right)$ and PA14_40260 $\left(\log _{2} \mathrm{FC}-3.39\right)$ encoding a putative pilus assembly protein and a conserved hypothetical protein, respectively. Interestingly, KEEG pathway analysis (see also further below) revealed that PA14_40260 encodes a protein involved in the pathway of quorum sensing whereas, curated search in both KEEG and PseudoCAP databases revealed that PA14_55940, the most down-regulated gene in the presence of pine honey, encodes a bacterial motility protein (fimbriae associated protein Flp/Fap pilin component) of the protein secretion/export apparatus (Type II secretion system) $[49,50]$. Our observations are in accordance with a relevant study, where manuka honey reduced the motility of $P$. aeruginosa through the suppression of flagellin-associated genes [25]. It is plausible that pine honey reduces in a similar way the motility thus reducing $P$. aeruginosa virulence.

Other genes that were also strongly down-regulated include $p h z S\left(\log _{2} \mathrm{FC}-4.16\right)$ and $\mathrm{M}\left(\log _{2} \mathrm{FC}-3.28\right)$ encoding a flavin-containing monooxygenase and a probable phenazinespecific methyltransferase respectively, oprC $\left(\log _{2} \mathrm{FC}-3.17\right)$ encoding an outer membrane copper receptor (pores ion channels), hwn ( $\left.\log _{2} \mathrm{FC}-3.50\right)$ encoding a putative halovibrin protein, $b k d B$ encoding a lipoamide acyltransferase component of branched-chain alphaketo acid dehydrogenase complex E2, lpdV (lipoamide dehydrogenase-Val) and chiC that encode a chitinase (Figure 2).

\subsubsection{Gene Ontology (GO) Enrichment Analysis}

In order to further investigate the biological functions and the metabolic pathways of DEGs in presence of pine honey, GO analysis was performed [50,61]. The most enriched GO categories among the DEGs are shown in Figure 3 and Supplementary Tables S4-S7.

In the Biological Processes (BP) category (total DEGs: 375, up-regulated: 177, downregulated: 198), the most enriched terms for up-regulated DEGs in presence of pine honey were related to "regulation of DNA-templated transcription," "siderophore transport," and "phosphorylation" whereas, in contrast, the most enriched BP GO terms for down-regulated DEGs were "oxidation-reduction process," "transmembrane transport," "proteolysis," "signal transduction," "biosynthetic process," "phenazine biosynthetic process," "bacterial chemotaxis," and "antibiotic biosynthetic process" (Figure 3A, Table S5). In the Cellular Component (CC) category (total DEGs: 138, up-regulated: 62, down-regulated: 76), the most enriched terms for up-regulated DEGs in presence of pine honey were related to "cell outer membrane" and "integral component of plasma membrane" whereas the most enriched CC GO terms for down-regulated DEGs were "integral component of membrane," "ATP-binding cassette (ABC) transporter complex," and "cytoplasm" (Figure 3B, Table S6). In addition, in this category, the most enriched GO term was "membrane." Furthermore, in the Molecular Function (MF) category (total DEGs: 513, up-regulated: 233, down-regulated: 
280) the most enriched terms for up-regulated DEGs in presence of pine honey were "DNA and ATP binding" whereas, "catalytic activity" and "flavin adenine dinucleotide binding" were the most enriched terms for down-regulated DEGs. Other highly enriched MF GO terms were "oxidoreductase activity" and "transmembrane transporter activity" (Figure 3C, Table S7).
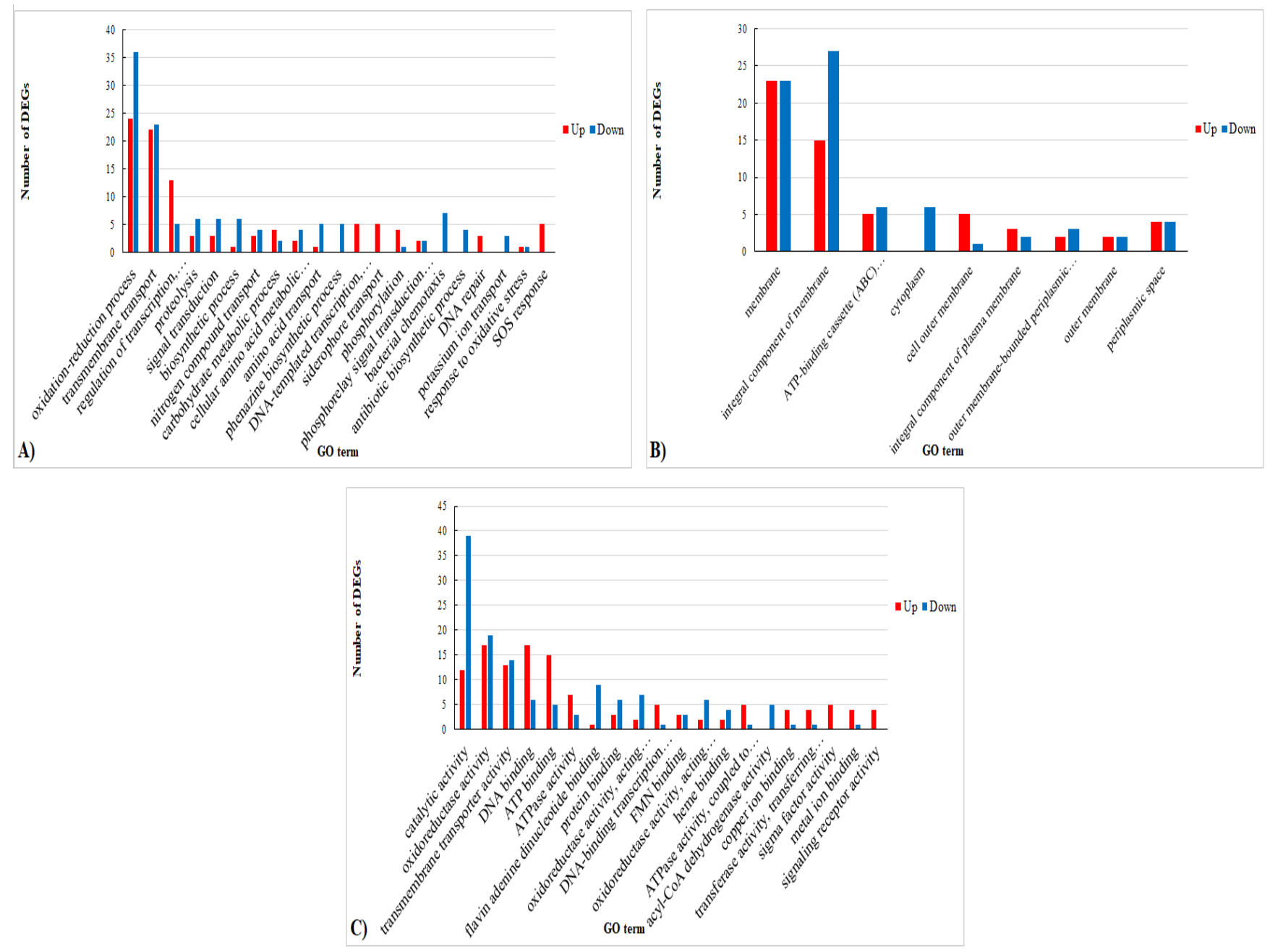

Figure 3. Gene Ontology categories of the DEGs. Three main categories were identified: (A) biological process (BP, total DEGs: 375, up-regulated: 177, down-regulated: 198) (B) cellular component (CC, total DEGs: 138, up-regulated: 62, down-regulated: 76) (C) molecular function (MF, total DEGs: 513, up-regulated: 233, down-regulated: 280).

\subsubsection{KEGG Pathway Enrichment Analysis}

Kyoto Encyclopedia of Genes and Genomes (KEGG) pathway enrichment analysis revealed that pine honey significantly affected several cellular pathways and induced the differential expression of genes involved in (but not limited to) two-component regulatory systems, ABC transporters, quorum sensing (QS), bacterial chemotaxis, and biofilm formation. Regarding the two-component regulatory systems, pine honey treatment caused significant up-regulation of 10 genes and down-regulation of 25 genes (Figure 4A). 

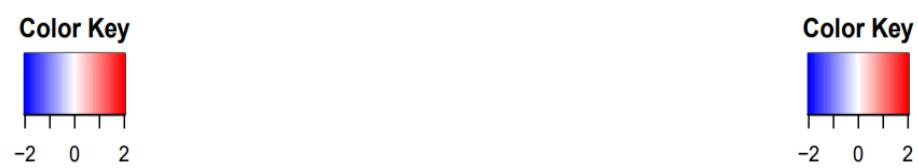

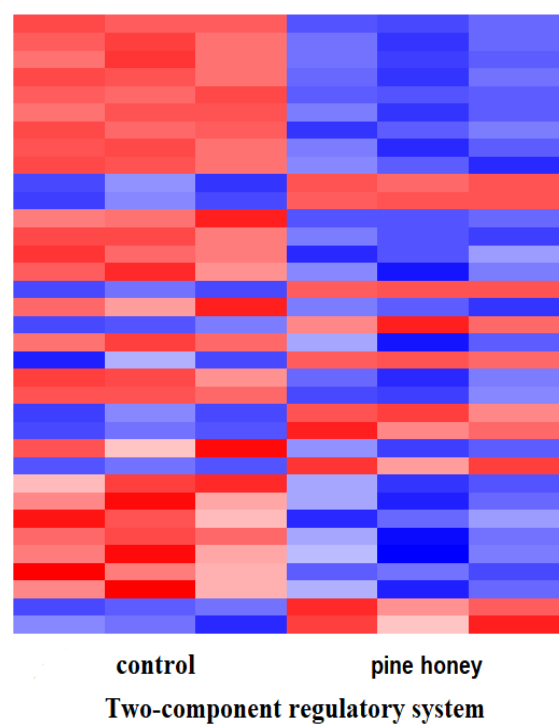

A)

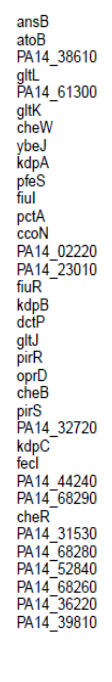

Two-component regulatory system

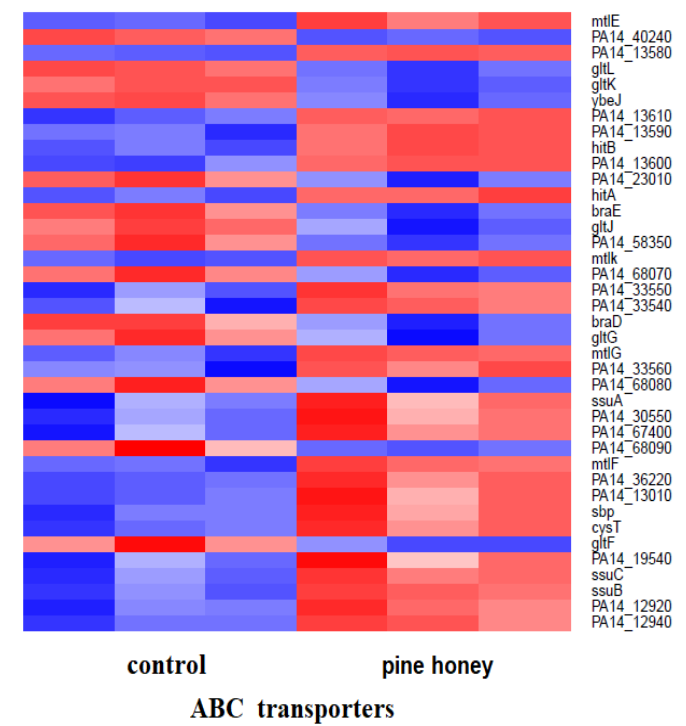

B)

Figure 4. Heatmaps show $\log _{2} \mathrm{FC}$ data of DEGs implicated in: (A) two-component regulatory system. (B) ABC transporters, according to KEGG analysis. The red and blue gradients indicate up- and down-regulated gene expression.

In treated samples, two genes ( $p f e S$ and pirR) encoding a sensor and response regulator respectively, were among the most up-regulated ( $\log _{2} \mathrm{FC} 1.61$ and 1.58, respectively). In contrast, the most down-regulated genes were atoB, PA14_38610, ansB, PA14_31530, $k d p A, B$ and $C\left(\log _{2}\right.$ FC ranged from -1.62 to -3.22$)$. These genes encode an acetyl-CoA acetyltransferase, a putative short-chain fatty acid transporter, a glutaminase-asparaginase, a putative acyl-CoA thiolase, and potassium-transporting ATPase chain $\mathrm{ABC}$, respectively. Other down-regulated DEGs include oprD encoding an outer membrane porin and cheW, encoding a putative purine-binding chemotaxis protein. In the $A B C$ transporter gene group the up-regulated were more prevalent than the down-regulated genes (Figure $4 \mathrm{~B}$ ). The most up-regulated genes were $m t l E, K, G\left(\log _{2} \mathrm{FC}\right.$ ranged from 1.56 to 3.89$)$ encoding putative ATP-binding component of $\mathrm{ABC}$ maltose/mannitol transporters whereas, the most downregulated genes were PA14_40240 and $g l t K, L$ encoding a putative ATP-binding/permease fusion and, putative permease and ATP-binding component of ABC transporter system respectively. Interestingly, apart from the down-regulated genes oprC and $D$, encoding outer membrane porins, oprB $\left(\log _{2} \mathrm{FC}-1.65\right)$ encoding a glucose/carbohydrate outer membrane porin, and PA14_58410 $\left(\log _{2} \mathrm{FC}-1.55\right)$ encoding putative membrane porin, were also down-regulated. In contrast, the genes mexF and $E$, encoding putative RND efflux transporter and RND efflux membrane fusion protein precursor, were up-regulated ( $\log _{2} \mathrm{FC}, 2.25$ and 2.42 , respectively). $\mathrm{OprC}$ is a porin abundant in the outer membrane vesicles involved in channel-forming and copper binding [62]. OprC transports copper, an essential trace element implicated in several physiological processes, into bacteria during copper deficiency. In a very recent study the authors showed that oprC deletion inhibited bacterial motility and quorum-sensing systems, as well as decreased lipopolysaccharide and pyocyanin levels in P. aeruginosa [62]. Interestingly, a previous study has shown that manuka honey decreased pyocyanin production in P. aeruginosa PA14, presumably via interaction with the MvfR quorum sensing network [63]. The oprD porin facilitates the diffusion of basic amino acids and peptides containing these residues. Moreover, it is implicated in carbapenem resistance [64]. On the other hand, the oprB porin has been associated with the diffusion of glucose across the outer membrane of $P$. aeruginosa thanks 
to the ABC transporter $g l t[65,66]$. Raneri et al. [67] have demonstrated that P. aeruginosa mutants defective in glucose uptake have pleiotropic phenotype and attenuated virulence in non-mammal infection models. In this study, both oprB porin and glt ABC transporter were down-regulated. Previous studies have shown that reduced permeability of the outer membrane through oprD impairment and overexpression of the major resistancenodulation-division (RND) efflux pump systems (MexAB-OprM, MexCD-OprJ, MexEFOprN, and MexXY-OprM), contribute to carbapenem resistance in $P$. aeruginosa $[68,69]$. In this study, oprD is down-regulated in contrast to mexF and mexE (components of MexEFOprN RND efflux pump system) which are up-regulated in the presence of pine honey. It is tempting to speculate that such differential gene expression might counteract the anti-bacterial activity of compounds (e.g., phytochemicals) contained in pine honey.

Furthermore, RNA-seq analysis revealed that a group of genes implicated in iron uptake and transport are up-regulated when $P$. aeruginosa PA14 is exposed to pine honey. These genes include $f p t A, f e c A, f p v A$, piu $A$, and ton $B$ ( $\log _{2}$ FC ranged from 1.05 to 2.43) encoding the $\mathrm{Fe}(\mathrm{III})$-pyochelin outer membrane receptor, a TonB-dependent siderophore receptor, the ferripyoverdine receptor, a putative outer membrane ferric siderophore receptor, and periplasmic protein TonB, respectively. Moreover, two genes $p c h D$ and $p c h E$, implicated in pyochelin biosynthesis, were up-regulated $\left(\log _{2} \mathrm{FC} 1.13\right.$ and 1.14 , respectively). Iron is a key nutrient, involved in many crucial biological processes. Therefore, it is essential for bacterial growth and virulence. In order to overcome restricted iron bioavailability, $P$. aeruginosa developed various strategies to acquire iron through the direct production of siderophores such as pyoverdine as well as pyochelin and the uptake of siderophores via TonB-dependent receptors (TBDRs) [70]. Several studies have shown that TBDRs could be employed in a "Trojan horse" strategy, in which the interaction between a siderophore and an antibiotic could significantly increase the antibiotic bioactivity, by facilitating its transport into the bacterial cell [71-73]. Previous reports have demonstrated the involvement of different TBDRs such as $p i u A, f p v A, f e c A$, and $f p t A$ in the uptake of siderophore-drug conjugates in $P$. aeruginosa $[73,74]$. Our data suggest that honey might impose an iron-limited environment for P. aeruginosa, which could be potentially exploited in combination with siderophore-antibiotic conjugates as an alternative approach to combat this multi-drug resistant pathogen.

Pine honey treatment significantly affected the expression of several genes involved in quorum sensing (QS), bacterial chemotaxis, and biofilm formation pathways (Figure 5A-C).

Interestingly, pine honey treatment provoked significant down-regulation of almost all genes involved in the above pathways. The values of $\log _{2} \mathrm{FC}$ ranged from -1.02 to -5.20 . The genes $p h z G 1$ and $G 2\left(\log _{2} \mathrm{FC}-4.08\right.$ and -3.95 , respectively) encode a probable pyrodoxamine $5^{\prime}$-phosphate oxidase whereas, the genes $\operatorname{las} A, B$, and $\operatorname{lec} B\left(\log _{2} \mathrm{FC}\right.$ $-1.90,-2.4$, and -2.97 respectively) encode a staphylolytic exoprotease preproenzyme, an elastase, and a fucose-binding lectin PA-IIL, respectively. In the biofilm formation pathway the identified genes were pa1L, PA14_34050,PA14_34070,PA14_34100,PA14_34030, and PA14_34000 ( $\log _{2}$ FC ranged from -1.02 to -2.9$)$ encoding a PA-I galactophilic lectin and conserved hypothetical proteins, respectively whereas, in the bacterial chemotaxis pathway the involved genes were PA14_61300, cheW, pct A, PA14_02220, PA14_58350, cheB, cheR ( $\log _{2} \mathrm{FC}$ ranged from -1.02 to -1.67 ) encoding various chemotaxis proteins (i.e., methyltransferase, methyl-accepting and purine-binding).

Furthermore, pine honey induced the differential expression of genes involved in SOS response such as lex $A, \operatorname{rec} A, N, X$, and PA14_25150 ( $\log _{2}$ FC ranged from 1.2 to 1.72). Similarly, Bouzo et al. (2020) have demonstrated that manuka honey significantly upregulated a wide range of genes involved in SOS response. 


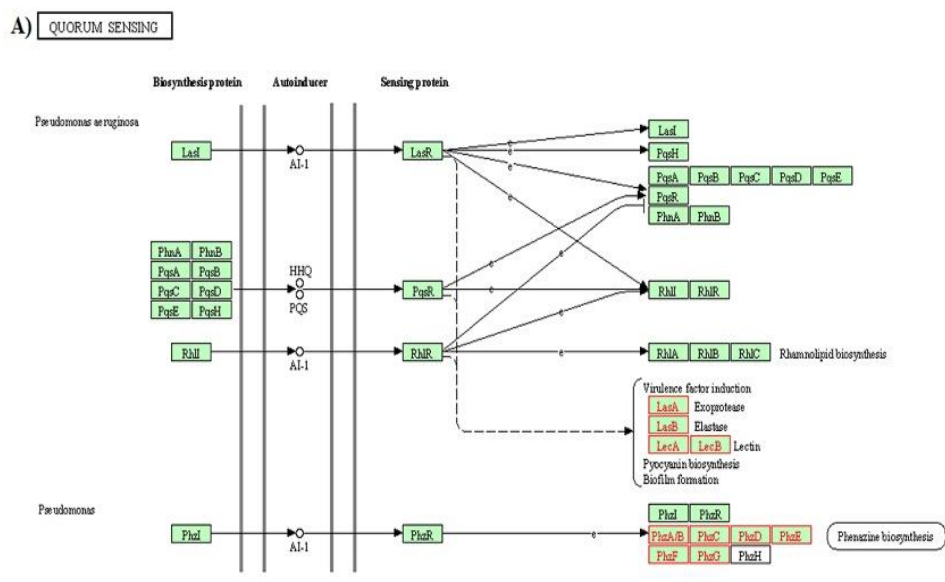

C) BIOFILM FORMATION · PSEUDOMONAS AERUGINOSA

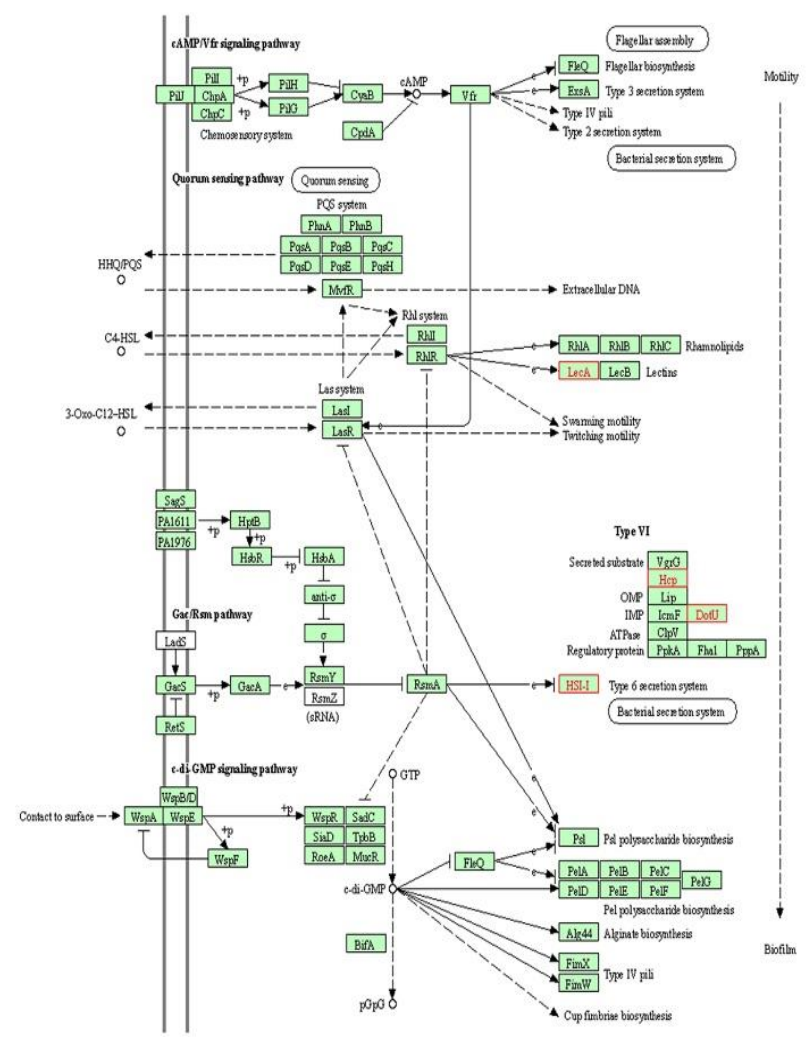

B) BACTERIAL CHEMOTAXIS
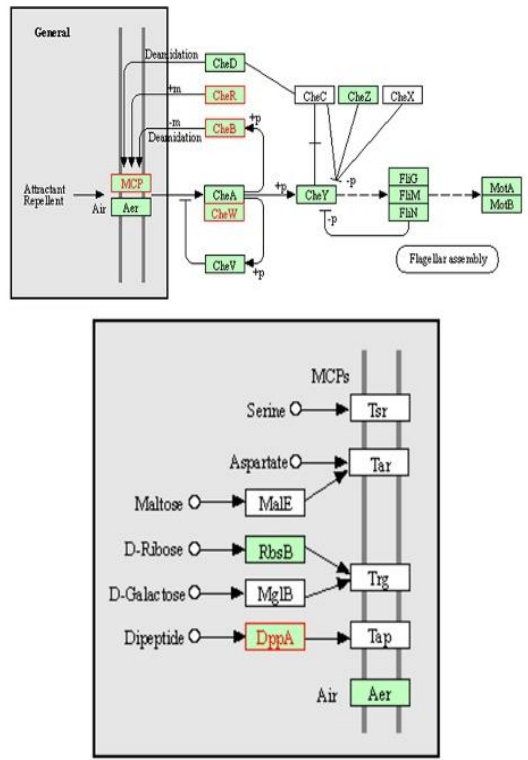

Figure 5. The KEGG pathways based on RNA high-throughput sequencing analysis of (A) quorum sensing, (B) bacterial chemotaxis, (C) biofilm formation. The red box indicate that the RNA expression of the gene is down-regulated, while the black box shows no changes in gene RNA expression.

Based on KEGG pathway and GO enrichment analysis, pine honey affected, at the transcriptome level, a wide range of biological processes and pathways in P. aeruginosa. The two-component regulatory system, the $\mathrm{ABC}$ transporter, and QS pathway were the most affected KEGG pathways in P. aeruginosa, since several up and down-regulated DEGs exhibited high fold changes (Figures 4 and 5). A two-component regulatory system plays a substantial role in the pathogenicity, bacterial adaptation, and biofilm formation [75,76]. The two-component regulatory system KEGG pathway (also called "two-component signal transduction system") enables bacteria to sense and respond to environmental or intracellular changes $[77,78]$. In this study, pine honey treatment induced the differential expression of several genes implicated in this pathway (Figure 4A). Among the down-regulated DEGs in the above pathway, cheW, $B$ and $R$, PA14_02220 and pctA genes encode chemotaxis 
proteins and transducers, respectively. The $c h e W, B$ and $R$ DEGs were also detected in the bacterial chemotaxis pathway (Figure $5 B$ ). Bacterial chemotaxis is the movement of bacterial cells in response to chemical stimuli [79]. According to Turner et al. [80], cheW, $B$, and $R$ genes, are required in acute but not chronic wound infections. These data suggest that pine honey treatment might impair the two-component system and bacterial chemotaxis pathways thus reducing the ability of $P$. aeruginosa to sense environmental stimuli and adapt accordingly. In comparison to the study of Bouzo et al. [56], manuka honey treatment did not affect at the same extent the two-component regulatory system and bacterial chemotaxis pathways.

Regarding the $\mathrm{ABC}$ transporter pathway, pine honey treatment caused significant up-regulation of 25 genes and down-regulation of 14 genes (Figure 4B). ABC (ATP-binding cassette) transporters play an important role in nutrients uptake [81]. In addition, $A B C$ transporter and two-component regulatory systems have a pivotal role in antimicrobial drug resistance [82]. It might be that up-regulation of several $A B C$ transporter genes might be related to nutrient uptake directly from pine honey (e.g., sugars).

Furthermore, KEEG analysis revealed that pine honey treatment significantly inhibited QS, bacterial chemotaxis, and biofilm formation pathways, since several key genes were down-regulated (Figure 5). In P. aeruginosa, three systems las, rhl, as well as pqs, which are forming an hierarchical network, play a crucial role in QS [83,84]. The las system positively regulates itself as well as the other two systems, while the $r h l$ and $p q s$ systems regulate each other (Figure 5A). In the first system, lasI catalyzes the synthesis of the signal molecule (AI-1), by binding las $R$ and activating the expression of many genes ( $p q s A, B, C, D, E, H$, $R, p h n A, B$ and rhlI, R) [85,86]. In the pqs system [87], genes such as pqs $A, B, C, D, H$, and $p h n A, B$, catalyze the synthesis of the signal molecules (HHQ or PQS), by binding $p q s R$ and activating the expression of various genes, including $p q s R$ as well as rhlI, $R$, whereas in the third system, rhlI catalyzes the synthesis of the signal molecule (AI-1), by binding $r h l R$ and activating the expression of other target genes ( $p q s R, p h n A, B, r h l I, R$ and $r h l A, B$ ) involved in the rhamnolipid biosynthesis [88]. Furthermore, in Figure 5A it is shown that the virulence factors las $A$ (exoprotease), lasB (elastase) and lecB (lectin), pyocyanin biosynthesis, and biofilm formation are co-regulated by the three QS systems (las, pqs, and rhl). In this study, pine honey treatment inhibited the expression of virulence genes such as las $A$, las $B$, pa1L (lecA) and lecB (Figure 5A). The gene lec $A$ is also involved in the biofilm formation pathway. In addition, the genes of the operon $p h z A B C D E F G$ involved in the phenazine biosynthesis, and the genes $p h z S$ and $M$ implicated in the pyocyanin biosynthesis, were down-regulated in a similar manner $\left(\log _{2} \mathrm{FC}>3\right)$. Previous studies have demonstrated that several enzymes of the biosynthetic operon $p h z A B C D E F G$, which is conserved across the fluorescent Pseudomonads, are involved in phenazine biosynthesis, through the conversion of chorismic acid to phenazine-1-carboxylic acid (PCA) [89,90]. P. aeruginosa has two functional copies ( $p h z 1$ and $p h z 2$ ) of this operon, which produce PCA. The conversion of PCA to phenazine-1-carboxamide as well as to 1-hydroxyphenazine is mediated by two genes $p h z H$ and $p h z S$, respectively. A third additional gene $p h z M$ is involved in PCA conversion to 5-methylphenazine-1-carboxylic acid betaine, which is further converted to pyocyanin by the action of $p h z S$ [89-91]. A recent study showed that phenazine production is associated with the antibiotic tolerance in $P$. aeruginosa biofilms [92].

Regarding the biofilm formation pathway, KEEG analysis revealed that pine honey treatment down-regulated key genes including pa1L (lecA) that encode a PA-I galactophilic lectin. Additionally, several genes encoding conserved hypothetical proteins (HIS-I; PA14_34000, PA14_34030, PA14_34050, PA14_34070 and PA14_34100) were also inhibited (Figure 5C). Interestingly, pine honey treatment also down-regulated PA14_34030 (Hcp) and PA14_34110 (DotU) implicated in the type VI secretion system of P. aeruginosa (Figure 5C) and PA14_55940 (putative pilus assembly protein) gene of the protein secretion/export apparatus (Type II secretion system) (Figure 5C). In the bacterial chemotaxis pathway, besides cheW, $B$ and $R$ genes, pine honey also down-regulated PA14_58350 (DppA), PA14_61300, and PA14_02220 (MCP) (Figure 5B). Collectively, these results indi- 
cate that pine honey down-regulated several genes involved in the QS system (virulence factors, phenazine production, chemotaxis, and biofilm formation pathway) thus reducing the fitness of $P$. aeruginosa to initiate infection or biofilm formation.

In a very recent study, transcriptome analysis of $P$. aeruginosa biofilm treated with Trigona honey revealed that roughly $13.5 \%$ of the down-regulated genes were biofilmassociated genes. Additionally, in the pathways involved in biofilm formation, an ultimate decrease in the expression levels of the D-GMP signaling pathway and diguanylate cyclases genes implicated in c-di-GMP formation, has been observed [93].

In comparison to the study of Bouzo et al. [56], manuka honey mainly down-regulated genes of the three different QS systems (las, rhl and pqs) while in this study pine honey treatment demonstrated a direct inhibitory effect on genes encoding virulence factors and phenazine biosynthesis. Interestingly, pine honey also down-regulated genes implicated in bacterial chemotaxis, biofilm formation, and bacterial secretion pathways, indicating a broader mode of action on the QS system, while this does not occur at such extent following manuka honey treatment.

\section{Conclusions}

The present study is the first to employ a global transcriptomic approach, in order to investigate the antibacterial effects and mode of action of pine honey. RNA-seq analysis revealed that pine honey significantly affected the trascriptomic profile of $P$. aeruginosa by increasing significantly the expression of 189 genes and by reducing significantly the expression of 274 genes. Specifically, pine honey treatment exerted a broad range of action on several pathways and biological processes including oxidation-reduction process, transmembrane transport, proteolysis, regulation of DNA-templated transcription, twocomponent regulatory systems, ABC transporters, and SOS response. Interestingly, pine honey might inhibit quorum sensing, bacterial chemotaxis, and biofilm formation since several differentially expressed genes involved in the above pathways were strongly downregulated. Overall, these data demonstrated that pine honey exerted an inhibitory effect in P. aeruginosa genome expression since more genes were down-regulated than up-regulated. These findings could potentially contribute to the treatment and control of $P$. aeruginosa infection and pathogenicity, helping to elucidate the molecular pathways and biological processes implicated in the antibacterial activity exerted by pine honey. Moreover, our results suggest that the use of pine honey in wound dressings could be an effective and economical approach to ameliorate wound healing.

Supplementary Materials: The following are available online at https:/ / www.mdpi.com/article/10 .3390/foods10050936/s1. Table S1: Differential gene expression results of HISAT2-DESeq2 package. Table S2: Differential gene expression results of de novo Trinity-edgeR package. Table S3: Differential gene expression results of reference genome guided analysis-Bowtie2-edgeR package. Table S4: Gene Ontology (all categories) of DEGs. Table S5: Gene Ontology (biological process category) of DEGs. Table S6: Gene Ontology (cellular component category) of DEGs. Table S7: Gene Ontology (molecular function category) of DEGs.

Author Contributions: I.K.: Investigation, methodology, data analysis and writing original draft. C.T.: Investigation, methodology, data analysis and writing original draft. M.N.: Data analysis and writing original draft. E.T.: Investigation and data analysis. T.G.D.: Review and editing. I.I.: Data analysis, review and editing. G.D.A.: Data analysis, review and editing. D.M.: Conceptualization, methodology, data analysis, writing original draft, review and editing, supervision, funding acquisition. All authors have read and agreed to the published version of the manuscript.

Funding: This work was supported by the General Secretariat for Research and Innovation (G.S.R.I) under the emblematic action "Honeybee Road". I.K. is recipient of a Postdoctoral Fellowship under the emblematic action "Honeybee Road". The research work was supported by the Hellenic Foundation for Research and Innovation (HFRI) under the HFRI PhD Fellowship grant (Fellowship Number: 545) for C.T.

Informed Consent Statement: Not applicable. 
Data Availability Statement: The raw RNA-seq data are available at NCBI Sequence Read Archive (NCBI SRA) under BioProject accession no. PRJNA705535. https:/ / www.ncbi.nlm.nih.gov/bioproject/ ?term=PRJNA705535 (accessed on 1 March 2021).

Acknowledgments: We thank Jean-Paul Pirnay (Laboratory for Molecular and Cellular Technology, Queen Astrid Military Hospital, Brussels, Belgium) who kindly provided Pseudomonas aeruginosa PA14 strain for the experiment.

Conflicts of Interest: The authors declare no conflict of interest.

\section{References}

1. Lee, D.J.; Jo, A.R.; Jang, M.C.; Nam, J.; Choi, H.J.; Choi, G.W.; Sung, H.Y.; Bae, H.; Ku, Y.G.; Chi, Y.T. Analysis of two quorum sensing-deficient isolates of Pseudomonas aeruginosa. Microb. Pathog. 2018, 119, 162-169. [CrossRef]

2. Faure, E.; Kwong, K.; Nguyen, D. Pseudomonas aeruginosa in chronic lung infections: How to adapt within the host? Front. Immunol. 2018, 9, 2416. [CrossRef]

3. Ruffin, M.; Brochiero, E. Repair process impairment by Pseudomonas aeruginosa in epithelial tissues: Major features and potential therapeutic avenues. Front. Cell Infect. Microbiol. 2019, 9, 182. [CrossRef] [PubMed]

4. El-Mahdy, R.; El-Kannishy, G. Virulence factors of carbapenem-resistant Pseudomonas aeruginosa in hospital-acquired infections in Mansoura, Egypt. Infect. Drug Resist. 2019, 12, 3455-3461. [CrossRef] [PubMed]

5. Nikolaidis, M.; Mossialos, D.; Oliver, S.; Amoutzias, G.D. Comparative analysis of the core proteomes among the Pseudomonas major evolutionary groups reveals species-specific adaptations for Pseudomonas aeruginosa and Pseudomonas chlororaphis. Diversity 2020, 12, 289. [CrossRef]

6. He, J.; Jia, X.; Yang, S.; Xu, X.; Sun, K.; Li, C.; Yang, T.; Zhang, L. Heteroresistance to carbapenems in invasive Pseudomonas aeruginosa infections. Int. J. Antimicrob. Agents 2018, 51, 413-421. [CrossRef]

7. Li, W.R.; Ma, Y.K.; Shi, Q.S.; Xie, X.B.; Sun, T.L.; Peng, H.; Huang, X.M. Diallyl disulfide from garlic oil inhibits virulence factors of Pseudomonas aeruginosa by inactivating key quorum sensing genes. Appl. Microbiol. Biotechnol. 2018, 102, 7555-7564. [CrossRef] [PubMed]

8. Pang, Z.; Raudonis, R.; Glick, B.R.; Lin, T.J.; Cheng, Z. Antibiotic resistance in Pseudomonas aeruginosa: Mechanisms and alternative therapeutic strategies. Biotechnol. Adv. 2019, 37, 177-192. [CrossRef]

9. Tacconelli, E.; Carrara, E.; Savoldi, A.; Harbarth, S.; Mendelson, M.; Monnet, D.L.; Pulcini, C.; Kahlmeter, G.; Kluytmans, J.; Carmeli, Y.; et al. Discovery, research, and development of new antibiotics: The WHO priority list of antibiotic-resistant bacteria and tuberculosis. Lancet Infect. Dis. 2018, 18, 318-327. [CrossRef]

10. McLoone, P.; Warnock, M.; Fyfe, L. Honey: A realistic antimicrobial for disorders of the skin. J. Microbiol. Immunol. Infect. 2016, 49, 161-167. [CrossRef] [PubMed]

11. Oryan, A.; Alemzadeh, E.; Moshiri, A. Biological properties and therapeutic activities of honey in wound healing: A narrative review and meta-analysis. J. Tissue Viability 2016, 25, 98-118. [CrossRef]

12. Khan, S.U.; Anjum, S.I.; Rahman, K.; Ansari, M.J.; Khan, W.U.; Kamal, S.; Khattak, B.; Muhammad, A.; Khan, H.U. Honey: Single food stuff comprises many drugs. Saudi J. Biol. Sci. 2018, 25, 320-325. [CrossRef]

13. Roshan, N.; Rippers, T.; Locher, C.; Hammer, K.A. Antibacterial activity and chemical characteristics of several Western Australian honeys compared to manuka honey and pasture honey. Arch. Microbiol. 2017, 199, 347-355. [CrossRef] [PubMed]

14. Kuś, P.M.; Szweda, P.; Jerković, I.; Tuberoso, C.I. Activity of Polish unifloral honeys against pathogenic bacteria and its correlation with colour, phenolic content, antioxidant capacity and other parameters. Lett. Appl. Microbiol. 2016, 62, 269-276. [CrossRef] [PubMed]

15. Grecka, K.; Kuś, P.M.; Worobo, R.W.; Szweda, P. Study of the anti-staphylococcal potential of honeys produced in Northern Poland. Molecules 2018, 23, 260. [CrossRef] [PubMed]

16. Bucekova, M.; Jardekova, L.; Juricova, V.; Bugarova, V.; Di Marco, G.; Gismondi, A.; Leonardi, D.; Farkasovska, J.; Godocikova, J.; Laho, M.; et al. Antibacterial activity of different blossom honeys: New findings. Molecules 2019, 24, 1573. [CrossRef]

17. Bucekova, M.; Bugárová, V.; Godocikova, J.; Majtan, J. Demanding new honey qualitative standard based on antibacterial activity. Foods 2020, 9, 1263. [CrossRef] [PubMed]

18. Anthimidou, E.; Mossialos, D. Antibacterial activity of Greek and Cypriot honeys against Staphylococcus aureus and Pseudomonas aeruginosa in comparison to manuka honey. J. Med. Food 2013, 16, 42-47. [CrossRef]

19. Stagos, D.; Soulitsiotis, N.; Tsadila, C.; Papaeconomou, S.; Arvanitis, C.; Ntontos, A.; Karkanta, F.; Androulaki, S.A.; Petrotos, K.; Spandidos, D.A.; et al. Antibacterial and antioxidant activity of different types of honey derived from Mount Olympus in Greece. Int. J. Mol. Med. 2018, 42, 726-734. [CrossRef]

20. Tsavea, E.; Mossialos, D. Antibacterial activity of honeys produced in Mount Olympus area against nosocomial and foodborne pathogens is mainly attributed to hydrogen peroxide and proteinaceous compounds. J. Apic. Res. 2019, 58, 1-8. [CrossRef]

21. Kwakman, P.H.S.; Zaat, S. Antibacterial components of honey. IUBMB Life 2012, 64, 48-55. [CrossRef] [PubMed]

22. Nolan, V.C.; Harrison, J.; Cox, J. Dissecting the antimicrobial composition of honey. Antibiotics 2019, 8, 251. [CrossRef] [PubMed]

23. Jenkins, R.; Burton, N.; Cooper, R. Effect of manuka honey on the expression of universal stress protein A in methicillin- resistant Staphylococcus aureus. Int. J. Antimicrob. Agents 2011, 37, 373-376. [CrossRef] [PubMed] 
24. Sindi, A.; Chawn, M.V.B.; Hernandez, M.E.; Green, K.; Islam, M.K.; Locher, C.; Hammer, K.A. Anti-biofilm effects and characterisation of the hydrogen peroxide activity of a range of Western Australian honeys compared to manuka and multifloral honeys. Sci. Rep. 2019, 9, 17666. [CrossRef]

25. Roberts, A.E.; Maddocks, S.E.; Cooper, R.A. Manuka honey reduces the motility of Pseudomonas aeruginosa by suppression of flagella-associated genes. J. Antimicrob. Chemother. 2015, 70, 716-725. [CrossRef]

26. Ahmed, A.A.; Salih, F.A. Low concentrations of local honey modulate Exotoxin A expression, and quorum sensing related virulence in drug-resistant Pseudomonas aeruginosa recovered from infected burn wounds. Iran J. Basic Med. Sci. 2019, 22, 568-575. [CrossRef] [PubMed]

27. Nikolopoulos, C. Morphology and Biology of the Species Marchalina Hellenica (Gennadius) (Hemiptera, Margarodidea-Coelostomidiinae); Agricultural College of Athens: Athens, Greece, 1965; p. 16.

28. de-Miguel, S.; Pukkala, T.; Yeşil, A. Integrating pine honeydew honey production into forest management optimization. Eur. J. For. Res. 2014, 133, 423-432. [CrossRef]

29. Tananaki, C.H.; Thrasyvoulou, A.; Giraudel, J.L.; Montury, M. Determination of volatile characteristics of Greek and Turkish pine honey samples and their classification by using Kohonen selforganizing maps. Food Chem. 2007, 101, 1687-1693. [CrossRef]

30. Bacandritsos, N.; Saitanis, C.; Papanastasiou, I. Morphology and life cycle of Marchalina hellenica (Gennadius) (Hemiptera: Margarodidae) on pine (Parnis Mt.) and fir (Helmos Mt.) forests of Greece. Ann. Soc. Entomol. Fr. 2004, 40, 169-176. [CrossRef]

31. Bouga, M.; Evangelou, V.; Lykoudis, D.; Cakmak, I.; Hatjina, F. Genetic structure of Marchalina hellenica (Hemiptera: Margarodidae) populations from Turkey: Preliminary mtDNA sequencing data. Biochem. Genet. 2011, 49, 683-694. [CrossRef]

32. Akbulut, M.; Ozcan, M.M.; Coklar, H. Evaluation of antioxidant activity, phenolic, mineral contents and some physicochemical properties of several pine honeys collected from Western Anatolia. Int. J. Food Sci. Nutr. 2009, 60, 577-589. [CrossRef]

33. Kaygusuz, H.; Tezcan, F.; Bedia Erim, F.; Yildiz, O.; Sahin, H.; Can, Z.; Kolayli, S. Characterization of Anatolian honeys based on minerals, bioactive components and principal component analysis. LWT-Food Sci. Technol. 2016, 68, 273-279. [CrossRef]

34. Kolayli, S.; Sahin, H.; Can, Z.; Yildiz, O.; Sahin, K. Honey shows potent inhibitory activity against the bovine testes hyaluronidase. Enzyme Inhib. Med. Chem. 2016, 31, 599-602. [CrossRef] [PubMed]

35. Gül, A.; Pehlivan, T. Antioxidant activities of some monofloral honey types produced across Turkey. Saudi J. Biol. Sci. 2018, 25. [CrossRef]

36. Alnaimat, S.; Wainwright, M.; Al'Abri, K. Antibacterial potential of honey from different origins: A comparsion with manuka honey. J. Microbiol. Biotechnol. Food Sci. 2012, 1, 1328-1338.

37. Ekici, L.; Osman, S.; Sibel, S.; Ismet, O. Determination of phenolic content, antiradical, antioxidant and antimicrobial activities of Turkish pine honey. Qual. Assur. Saf. Crop. Foods 2014, 6, 439-444. [CrossRef]

38. Lei, R.; Ye, K.; Gu, Z.; Sun, X. Diminishing returns in next-generation sequencing (NGS) transcriptome data. Gene 2015, 557, 82-87. [CrossRef] [PubMed]

39. Łabaj, P.P.; Kreil, D.P. Sensitivity, specificity, and reproducibility of RNA-Seq differential expression calls. Biol. Direct. 2016, 11, 66. [CrossRef]

40. Liu, X.; Shen, B.; Du, P.; Wang, N.; Wang, J.; Li, J.; Sun, A. Transcriptomic analysis of the response of Pseudomonas fluorescens to epigallocatechin gallate by RNA-seq. PLoS ONE 2017, 12, e0177938. [CrossRef]

41. Li, Z.; Xu, M.; Wei, H.; Wang, L.; Deng, M. RNA-seq analyses of antibiotic resistance mechanisms in Serratia marcescens. Mol. Med. Rep. 2019, 20, 745-754. [CrossRef] [PubMed]

42. Szweda, P. Antimicrobial activity of honey. In Honey Analysis; Arnaut de Toledo, V.A., Ed.; InTech: Madrid, Spain, 2017; pp. 215-232. [CrossRef]

43. Kwakman, P.H.S.; Te Velde, A.A.; de Boer, L.; Speijer, D.; Vandenbroucke-Grauls, C.M.; Zaat, S.A.J. How honey kills bacteria. FASEB J. 2010, 24, 2576-2582. [CrossRef]

44. Bolger, A.M.; Lohse, M.; Usadel, B. Trimmomatic: A flexible trimmer for Illumina sequence data. Bioinformatics 2014, 30, 2114-2120. [CrossRef]

45. Kim, D.; Langmead, B.; Salzberg, S.L. HISAT: A fast spliced aligner with low memory requirements. Nat. Methods 2015, 12, 357-360. [CrossRef]

46. Liao, Y.; Smyth, G.K.; Shi, W. FeatureCounts: An efficient general purpose program for assigning sequence reads to genomic features. Bioinformatics 2013, 30, 923-930. [CrossRef]

47. Love, M.I.; Huber, W.; Anders, S. Moderated estimation of fold change and dispersion for RNA-seq data with DESeq2. Genome Biol. 2014, 15, 550. [CrossRef]

48. Young, M.D.; Wakefield, M.J.; Smyth, G.K.; Oshlack, A. Gene ontology analysis for RNA-seq: Accounting for selection bias. Genome Biol. 2010, 11, R14. [CrossRef] [PubMed]

49. Kanehisa, M.; Goto, S.; Furumichi, M.; Tanabe, M.; Hirakawa, M. KEGG for representation and analysis of molecular networks involving diseases and drugs. Nucleic Acids Res. 2010, 38, D355-D360. [CrossRef] [PubMed]

50. Winsor, G.L.; Griffiths, E.J.; Lo, R.; Dhillon, B.K.; Shay, J.A.; Brinkman, F. Enhanced annotations and features for comparing thousands of Pseudomonas genomes in the Pseudomonas genome database. Nucleic Acids Res. 2016, 44, D646-D653. [CrossRef] [PubMed] 
51. Grabherr, M.G.; Haas, B.J.; Yassour, M.; Levin, J.Z.; Thompson, D.A.; Amit, I.; Adiconis, X.; Fan, L.; Raychowdhury, R.; Zeng, Q.; et al. Full-length transcriptome assembly from RNA-Seq data without a reference genome. Nat. Biotechnol. 2011, $29,644-652$. [CrossRef] [PubMed]

52. Langmead, B.; Salzberg, S.L. Fast gapped-read alignment with Bowtie 2. Nat. Methods 2012, 9, 357-359. [CrossRef]

53. Robinson, M.D.; McCarthy, D.J.; Smyth, G.K. edgeR: A bioconductor package for differential expression analysis of digital gene expression data. Bioinformatics 2010, 26, 139-140. [CrossRef]

54. Wecke, T.; Mascher, T. Antibiotic research in the age of omics: From expression profiles to interspecies communication. J. Antimicrob. Chemother. 2011, 66, 2689-2704. [CrossRef] [PubMed]

55. Bernier, S.P.; Surette, M.G. Concentration-dependent activity of antibiotics in natural environments. Front. Microbiol. 2013, 4, 20. [CrossRef] [PubMed]

56. Bouzo, D.; Cokcetin, N.; Li, L.; Ballerin, G.; Bottomley, A.; Lazenby, J.; Whitchurch, C.; Paulsen, I.; Hassan, K.; Harry, E. Characterizing the mechanism of action of an ancient antimicrobial, manuka honey, against Pseudomonas aeruginosa using modern transcriptomics. MSystems 2020, 5, e00106-20. [CrossRef]

57. Brown, S.M.; Howell, M.L.; Vasil, M.L.; Anderson, A.J.; Hassett, D.J. Cloning and characterization of the katB gene of Pseudomonas aeruginosa encoding a hydrogen peroxide-inducible catalase: Purification of katB, cellular localization, and demonstration that it is essential for optimal resistance to hydrogen peroxide. J. Bacteriol. 1995, 177, 6536-6544. [CrossRef] [PubMed]

58. Mossialos, D.; Tavankar, G.; Zlosnik, J.; Williams, H. Defects in a quinol oxidase lead to loss of katC catalase activity in Pseudomonas aeruginosa: KatC activity is temperature dependent and it requires an intact disulphide bond formation system. Biochem. Biophys. Res. Commun. 2006, 341, 697-702. [CrossRef] [PubMed]

59. Wongsaroj, L.; Saninjuk, K.; Romsang, A.; Duang-Nkern, J.; Trinachartvanit, W.; Vattanaviboon, P.; Mongkolsuk, S. Pseudomonas aeruginosa glutathione biosynthesis genes play multiple roles in stress protection, bacterial virulence and biofilm formation. PLoS ONE 2018, 13, e0205815. [CrossRef] [PubMed]

60. Tang, D.; Wang, X.; Wang, J.; Wang, M.; Wang, Y.; Wang, W. Choline-betaine pathway contributes to hyperosmotic stress and subsequent lethal stress resistance in Pseudomonas protegens SN15-2. J. Biosci. 2020, 45, 85. [CrossRef]

61. Ashburner, M.; Ball, C.A.; Blake, J.A.; Botstein, D.; Butler, H.; Cherry, J.M.; Davis, A.P.; Dolinski, K.; Dwight, S.S.; Eppig, J.T.; et al. Gene ontology: Tool for the unification of biology. The Gene Ontology Consortium. Nat. Genet. 2000, 25, 25-29. [CrossRef]

62. Gao, P.; Guo, K.; Pu, Q.; Wang, Z.; Lin, P.; Qin, S.; Khan, N.; Hur, J.; Liang, H.; Wu, M. OprC impairs host defense by increasing the quorum-sensing-mediated virulence of Pseudomonas aeruginosa. Front. Immunol. 2020, 11, 1696. [CrossRef] [PubMed]

63. Wang, R.; Starkey, M.; Hazan, R.; Rahme, L.G. Honey's ability to counter bacterial infections arises from both bactericidal compounds and QS inhibition. Front. Microbiol. 2012, 3, 144. [CrossRef] [PubMed]

64. Pirnay, J.P.; De Vos, D.; Mossialos, D.; Vanderkelen, A.; Cornelis, P.; Zizi, M. Analysis of the Pseudomonas aeruginosa oprD gene from clinical and environmental isolates. Environ. Microbiol. 2002, 4, 872-882. [CrossRef]

65. Hancock, R.E.; Speert, D.P. Antibiotic resistance in Pseudomonas aeruginosa: Mechanisms and impact on treatment. Drug Resist. Updat. 2000, 3, 247-255. [CrossRef]

66. Adewoye, L.O.; Worobec, E.A. Identification and characterization of the gltK gene encoding a membrane-associated glucose transport protein of Pseudomonas aeruginosa. Gene 2000, 253, 323-330. [CrossRef]

67. Raneri, M.; Pinatel, E.; Peano, C.; Rampioni, G.; Leoni, L.; Bianconi, I.; Jousson, O.; Dalmasio, C.; Ferrante, P.; Briani, F. Pseudomonas aeruginosa mutants defective in glucose uptake have pleiotropic phenotype and altered virulence in non-mammal infection models. Sci. Rep. 2018, 8, 16912. [CrossRef]

68. Lister, P.D.; Wolter, D.J.; Hanson, N.D. Antibacterial-resistant Pseudomonas aeruginosa: Clinical impact and complex regulation of chromosomally encoded resistance mechanisms. Clin. Microbiol. Rev. 2009, 22, 582-610. [CrossRef] [PubMed]

69. Quale, J.; Bratu, S.; Gupta, J.; Landman, D. Interplay of efflux system, ampC, and oprD expression in carbapenem resistance of Pseudomonas aeruginosa clinical isolates. Antimicrob. Agents Chemother. 2006, 50, 1633-1641. [CrossRef] [PubMed]

70. Mossialos, D.; Amoutzias, G.D. Siderophores in fluorescent pseudomonads: New tricks from an old dog. Future Microbiol. 2007, 2, 387-395. [CrossRef]

71. Budzikiewicz, H. Siderophore-antibiotic conjugates used as trojan horses against Pseudomonas aeruginosa. Curr. Top. Med. Chem. 2001, 1, 73-82. [CrossRef] [PubMed]

72. Mossialos, D.; Amoutzias, G.D. Role of siderophores in cystic fibrosis pathogenesis: Foes or friends? Int. J. Med. Microbiol. 2009, 299, 87-98. [CrossRef]

73. Mislin, G.L.; Schalk, I.J. Siderophore-dependent iron uptake systems as gates for antibiotic Trojan horse strategies against Pseudomonas aeruginosa. Metallomics 2014, 6, 408-420. [CrossRef]

74. Luscher, A.; Moynié, L.; Auguste, P.S.; Bumann, D.; Mazza, L.; Pletzer, D.; Naismith, J.H.; Köhler, T. TonB-dependent receptor repertoire of Pseudomonas aeruginosa for uptake of siderophore-drug conjugates. Antimicrob. Agents Chemother. 2018, 62, e00097-18. [CrossRef]

75. Francis, V.I.; Stevenson, E.C.; Porter, S.L. Two-component systems required for virulence in Pseudomonas aeruginosa. FEMS Microbiol. Lett. 2017, 364, fnx104. [CrossRef] [PubMed]

76. Bhagirath, A.Y.; Li, Y.; Patidar, R.; Yerex, K.; Ma, X.; Kumar, A.; Duan, K. Two component regulatory systems and antibiotic resistance in Gram-negative pathogens. Int. J. Mol. Sci. 2019, 20, 1781. [CrossRef] 
77. Tiwari, S.; Jamal, S.B.; Hassan, S.S.; Carvalho, P.; Almeida, S.; Barh, D.; Ghosh, P.; Silva, A.; Castro, T.; Azevedo, V. Twocomponent signal transduction systems of pathogenic bacteria as targets for antimicrobial therapy: An overview. Front. Microbiol. 2017, 8, 1878. [CrossRef] [PubMed]

78. Hirakawa, H.; Kurushima, J.; Hashimoto, Y.; Tomita, H. Progress overview of bacterial two-component regulatory systems as potential targets for antimicrobial chemotherapy. Antibiotics 2020, 9, 635. [CrossRef]

79. Hazelbauer, G.L. Bacterial chemotaxis: The early years of molecular studies. Annu. Rev. Microbiol. 2012, 66, 285-303. [CrossRef]

80. Turner, K.H.; Everett, J.; Trivedi, U.; Rumbaugh, K.P.; Whiteley, M. Requirements for Pseudomonas aeruginosa acute burn and chronic surgical wound infection. PLoS Genet. 2014, 10, e1004518. [CrossRef]

81. Pletzer, D.; Braun, Y.; Dubiley, S.; Lafon, C.; Köhler, T.; Page, M.; Mourez, M.; Severinov, K.; Weingart, H. The Pseudomonas aeruginosa PA14 ABC transporter NppA1A2BCD is required for uptake of peptidyl nucleoside antibiotics. J. Bacteriol. 2015, 197, 2217-2228. [CrossRef] [PubMed]

82. Ahmad, A.; Majaz, S.; Nouroz, F. Two-component systems regulate ABC transporters in antimicrobial peptide production, immunity and resistance. Microbiology 2020, 166, 4-20. [CrossRef] [PubMed]

83. Guo, Q.; Kong, W.N.; Jin, S.; Chen, L.; Xu, Y.Y.; Duan, K.M. PqsR-dependent and PqsR-independent regulation of motility and biofilm formation by PQS in Pseudomonas aeruginosa PAO1. J. Basic Microbiol. 2014, 54, 633-643. [CrossRef] [PubMed]

84. Lee, J.; Zhang, L. The hierarchy quorum sensing network in Pseudomonas aeruginosa. Protein Cell 2015, 6, 26-41. [CrossRef] [PubMed]

85. Passador, L.; Cook, J.M.; Gambello, M.J.; Rust, L.; Lglewski, B.H. Expression of Pseudomonas aeruginosa virulence genes requires cell-to-cell communication. Science 1993, 260, 1127-1130. [CrossRef]

86. Finch, R.G.; Pritchard, D.I.; Bycroft, B.W.; Williams, P.; Stewart, G.S. Quorum sensing: A novel target for anti-infective therapy. J. Antimicrob. Chemother. 1998, 42, 569-571. [CrossRef]

87. Williams, P.; Cámara, M. Quorum sensing and environmental adaptation in Pseudomonas aeruginosa: A tale of regulatory networks and multifunctional signal molecules. Curr. Opin. Microbiol. 2009, 12, 182-191. [CrossRef] [PubMed]

88. Latifi, A.; Foglino, M.; Tanaka, K.; Williams, P.; Lazdunski, A. A hierarchical quorum-sensing cascade in Pseudomonas aeruginosa links the transcriptional activators LasR and RhlR (VsmR) to expression of the stationary-phase sigma factor RpoS. Mol. Microbiol. 1996, 21, 1137-1146. [CrossRef]

89. Mavrodi, D.V.; Blankenfeldt, W.; Thomashow, L.S. Phenazine compounds in fluorescent Pseudomonas spp. biosynthesis and regulation. Ann. Rev. Phytopathol. 2006, 44,417-445. [CrossRef]

90. Mavrodi, D.V.; Peever, T.L.; Mavrodi, O.V.; Parejko, J.A.; Raaijmakers, J.M.; Lemanceau, P.; Mazurier, S.; Heide, L.; Blankenfeldt, W.; Weller, D.M.; et al. Diversity and evolution of the phenazine biosynthesis pathway. Appl. Environ. Microbiol. 2010, 76, 866-879. [CrossRef]

91. Mavrodi, D.V.; Bonsall, R.F.; Delaney, S.M.; Soule, M.J.; Phillips, G.; Thomashow, L.S. Functional analysis of genes for biosynthesis of pyocyanin and phenazine-1-carboxamide from Pseudomonas aeruginosa PAO1. J. Bacteriol. 2001, 183, 6454-6465. [CrossRef]

92. Schiessl, K.T.; Hu, F.; Jo, J.; Nazia, S.; Wang, B.; Price-Whelan, A.; Min, W.; Dietrich, L. Phenazine production promotes antibiotic tolerance and metabolic heterogeneity in Pseudomonas aeruginosa biofilms. Nat. Commun. 2019, 10, 762. [CrossRef]

93. Seder, N.; Abu Bakar, M.H.; Abu Rayyan, W.S. Transcriptome analysis of Pseudomonas aeruginosa biofilm following the exposure to Malaysian stingless bee honey. Adv. Appl. Bioinform. Chem. 2021, 14, 1-11. [CrossRef] [PubMed] 